\title{
A EDUCAÇÃO BRASILEIRA: PERSPECTIVAS PARA A FORMAÇÃO OMNILATERAL EM TEMPOS DE CAPITALISMO
}

\author{
Alexandra Vanessa de Moura Baczinski ${ }^{1}$, Sueli Ribeiro Comar ${ }^{2}$ \\ ${ }^{1}$ Doutoranda em Educação pela Universidade Federal de Pelotas - UFPel, Pelotas, RS. Atualmente é professora da \\ Universidade Estadual do Oeste do Paraná - Unioeste, Francisco Beltrão, PR. E-mail: alexandra.vanessa@hotmail.com \\ ${ }^{2}$ Doutora em Educação pela Universidade Federal de Pelotas - UFPel, Pelotas, RS. Atualmente é professora da \\ Universidade Estadual do Oeste do Paraná - Unioeste, Francisco Beltrão, PR.
}

\section{RESUMO}

O objetivo do artigo é sinalizar que a educação escolar brasileira contemporânea pode contribuir significativamente com o processo de formação omnilateral dos sujeitos, mesmo em tempos de neoliberalismo. Não se trata de uma visão ingênua de educação, mas acreditar nas pesquisas e estudos feitos ao longo das últimas décadas, a exemplo da pedagogia histórico-crítica, que nos instrumentaliza, para o embate, tão necessário na atualidade. Para organizar a discussão, dois tópicos se complementam. 0 primeiro traz elementos sobre o formato atual da educação brasileira, desenhado pelo perfil neoliberal que, conduzido pelas orientações internacionais, consolidam a Nova Gestão Pública. Esta forma de gerir a educação, define o que temos hoje: educação para competências, habilidades, meritocracia entre outras categorias as quais inserem a lógica do mercado neste setor. Reconhecido os desafios postos por este formato de educação, o segundo tópico do artigo, sinaliza possibilidades para a formação omnilateral a partir de elementos referentes ao materialismo histórico dialético e a pedagogia histórico-crítica. A metodologia consiste no estudo bibliográfico dessas duas perspectivas. Por fim, acreditamos que uma outra educação é possivel, pois, já temos suporte teórico suficiente, para uma práxis mais humanizadora de educação. Como resultado, defendemos a perspectiva e o destemor diante das reformas que colocam a educação cada vez mais a serviço do capital.

Palavras-chave: Educação omnilateral. Neoliberalismo. Pedagogia Histórico-Crítica.

\section{BRAZILIAN EDUCATION: PERSPECTIVES FOR OMNILATERAL TRAINING IN TIMES OF CAPITALISM}

\section{ABSTRACT}

The objective of the article is to indicate that contemporary Brazilian school education can contribute significantly to the process of all-round training of subjects, even in times of neoliberalism. It is not a naive vision of education, but rather to believe in the researches and studies made over the last decades, such as Critical Historical Pedagogy, which equips us for the struggle, which is so necessary today. To organize the discussion, two topics complement each other. The first presents elements about the current format of Brazilian education, designed by the neoliberal profile that, led by the international guidelines, consolidate the New Public Management. This way of managing education, defines what we have today: education for skills, skills, meritocracy among other categories which insert the logic of the market in this sector. Recognized the challenges posed by this format of education, the second topic of the article, indicates possibilities for the omnilateral formation from elements referring to dialectical historical materialism and critical historical pedagogy. The methodology consists of the bibliographic study of these two perspectives. Finally, we believe that another education is possible, because we already have sufficient theoretical support for a more humanizing praxis of education. As a result, we expect perspective and fearlessness in the face of reforms that place education increasingly at the service of capital.

Keywords: Omnilateral Education. Neoliberalism. Critical Historical Pedagogy. 


\section{EDUCACIÓN BRASILEÑA: PERSPECTIVAS PARA LA FORMACIÓN OMNILATERAL EN TIEMPOS DE CAPITALISMO}

RESUMEN: El objetivo del artículo es señalar que la educación escolar brasileña contemporánea puede contribuir significativamente con el proceso de formación omnilateral de los sujetos, incluso en tiempos de neoliberalismo. No se trata de una visión ingenua de educación, sino creer en las investigaciones y estudios hechos a lo largo de las últimas décadas, a ejemplo de la Pedagogía Histórico Critica, que nos instrumentaliza, para el embate, tan necesario en la actualidad. Para organizar la discusión, dos tópicos se complementan. El primero trae elementos sobre el formato actual de la educación brasileña, diseñado por el perfil neoliberal que, conducido por las orientaciones internacionales, consolidan la Nueva Gestión Pública. Esta forma de gestionar la educación, define lo que tenemos hoy: educación para competencias, habilidades, meritocracia entre otras categorías que inserta la lógica del mercado en este sector. Reconocido los desafíos planteados por este formato de educación, el segundo tópico del artículo, señala posibilidades para la formación omnilateral a partir de elementos referentes al materialismo histórico dialéctico y la pedagogía histórica crítica. La metodología consiste en el estudio bibliográfico de esas dos perspectivas. Por último, creemos que otra educación es posible, pues, ya tenemos soporte teórico suficiente, para una praxis más humanizadora de educación. Como resultado, esperamos la perspectiva y el temor frente a las reformas que ponen la educación cada vez más al servicio del capital.

Palabras clave: Educación omnilateral. Neoliberalismo. Pedagogía Histórico-Crítica.

\section{INTRODUÇÃO}

Não é por acaso que iniciamos este texto com a frase acima, mas sim, é uma legítima tentativa de ir na contramão das reformas lançadas pelo Estado em direção a educação brasileira, cujo horizonte parece se distanciar cada vez mais em ralação às expectativas de uma formação omnilateral pautada nas diversas áreas do conhecimento que permitiu o processo humanizador ao longo da história.

O cenário exige um passo adiante e a expectativa frente à desesperança, isso é o que justifica a elaboração deste texto cujo objetivo central é sinalizar que a educação escolar brasileira contemporânea pode contribuir significativamente com o processo de formação omnilateral dos sujeitos, mesmo em tempos de neoliberalismo. Não se trata de uma visão ingênua de educação, mas acreditar nas pesquisas e estudos feitos ao longo das últimas décadas, a exemplo da pedagogia históricocrítica, que nos instrumentaliza, para o embate, tão necessário na atualidade. Para organizar a discussão, dois tópicos se complementam. O primeiro traz elementos sobre o formato atual da educação brasileira, no sentido de identificar o formato neoliberal conduzido pelas orientações internacionais, cuja matriz é a Nova Gestão Pública. Reconhecido os desafios postos por este formato de educação, o segundo tópico do artigo, sinaliza possibilidades para uma educação que ultrapasse a lógica de mercado.

Como proposta metodologica, utilizamos o estudo bibliográfico (FONSECA, 2002), o qual baseia-se em leituras analíticas de referências teóricas, especialmente aquelas que sustentam a perspectiva do materialismo histórico dialético e da pedagogia histórico-crítica, representado por autores como Marx (1978, 2012), Batista (1994), Anderson (1995), Casassus(2001) e Saviani (2003). Isso tudo por acreditarmos que uma outra educação é possivel, pois, já temos suporte teórico suficiente, para uma práxis mais humanizadora em educação. Como resultado, esperarmos a perspectiva e o destemor frente as reformas que colocam a educação cada vez mais a serviço do capital.

Partindo do eixo central do texto, Educação, estruturamos esta reflexão teórica em dois momentos, no primeiro discutiremos sobre a nova gestão pública neoliberal analisando as reformas de Estado em atendimento as demandas neoliberais, servindo de contextualização para compreender a educação escolar, o trabalho realizado ao longo da história e o papel que potencialmente tem condiçoes de realizar como contraposição às exigencias neoliberais. No segundo momento, apresentaremos uma reflexão crítica em defesa da educação escolar para além das diretrizes do 
capital, uma educação que contribua para a formação integral do ser humano.

\section{EDUCAÇÃO A SERVIÇO DO CAPITAL: NOVA GESTÃO PÚBLICA NEOLIBERAL}

As orientações para o setor educacional da América Latina se intensificam após 1990, tendo apoio e articulação das agências internacionais. As medidas, de cunho neoliberal, trouxeram elementos para a submissão da educação, a lógica do mercado. Categorias como gerencialismo, competição, monitoramento, meritocracia e comparações, foram recorrentes nesse processo. Especificamente no campo econômico, as reformas foram justificadas pela incapacidade do Estado em gerir este setor (CASASSUS, 2001), o que implicou na organização de um novo cenário com perfil neoliberal, elemento base para a reforma desse Estado incapaz e oneroso.

No sentido de reorganizar o perfil do Estado, o papel do Banco Mundial, Banco Internacional para o Desenvolvimento, Organização Mundial do Comércio, Fundo Monetário Internacional entre outras do sistema ONU, foram cruciais. $\mathrm{Na}$ análise de Batista (1994) este foi o momento exato para as economias centrais, reforçarem a importância das reformas como meio de concessão e ajuda financeira externa, bilateral ou multilateral. Na mesma perspectiva Pereira $(1997$, p. 8 ) indica que havia entre os países centrais, a "intensão de criar certo consenso sobre as origens da crise da América Latina, e as reformas necessárias para solucioná-las".

Estabeleceu-se, pontualmente, uma estratégia econômica para reorganizar o Estado, regulada pela Nova Gestão Pública, com princípios da eficiência, resultados imediatos, comparações, premiações. Mas que se esclareça, Nova Gestão Pública, não é sinônimo de Reforma do Estado ou processos resultantes de uma mesma fórmula simples. $O$ documento elaborado pelo Centro Latino-Americano de Administração para o Desenvolvimento (CLAD) traz uma distinção interessante desse processo, ao identificar que a Reforma do Estado está inserida na "primeira geração de reformas" (CLAD, 1998, p. 122) marcada pela redução do tamanho do Estado em decorrência da falência do Estado de Bem-Estar ou os 30 anos Gloriosos do pós-guerra como bem nomeou Anderson (1995). Na contramão dessa forma de organização do Estado, inicia-se a implantação de um programa marcadamente neoliberal, especialmente após 1979, com o advento do governo de Thatcher na Inglaterra, momento no qual os princípios neoliberais na sua forma mais original puderam ser visualizados pela "elevação da taxa de juros, redução de impostos sobre altos rendimentos, criação de desemprego massivo, legislação antisindical e privatização de setores como habitação, energia, água, eletricidade" (ANDERSON, 1995, p.4). Esta mudança administrativa, inaceitável nos anos de 1950 e 1960, entra em cena, como medida para a retomada e crescimento da economia.

Com a década de 1980, ajustes econômicos similares são aplicados nos Estados Unidos durante a gestão de Ronald Reagan. Mesmo em economia avançada como os Estados Unidos, o neoliberalismo assume contornos diferentes, mas não menos impactantes para a sociedade (ANDERSON, 1995).

Para a América Latina, as mesmas orientações para reforma do tamanho do Estado foram direcionadas aos países em desenvolvimento, lembrando a primeira geração de reformas (CLAD, 1998). Tudo isso reforçado pelas metas expostas no Consenso de Washington ${ }^{1}$. Este evento se constitui em um conjunto de propostas de políticas e reformas com caráter receituário, estruturadas internacionalmente para amparar a América Latina de certa ineficiência do Estado. Vale ressaltar que o Consenso de Washington ${ }^{2}$ também colocou em questão as ideias Keynesianas $^{3}$ que expressa um modelo de desenvolvimento econômico ajustado pela planificação conservadora (FIORI, 2001).

Em oposição à política Keynesiana, as propostas para a América Latina validam certa governabilidade necessária para a efetivação das reformas pretendidas. Na leitura dos organismos internacionais, seria necessária a definição do

\footnotetext{
${ }^{2} \mathrm{~A}$ denominação Consenso de Washington foi assim descrita em 1990, pelo economista norte-americano John Williamson. A magnitude conceitual desse evento pode ser atribuída ao fato de concentrar interesses do governo, do Banco Mundial e de agências como o Fundo Monetário Internacional. Não se tratou especificamente de ideias inéditas sobre a economia, mas reforçar os planos de desenvolvimento no sentido de superar a crise econômica dos países em desenvolvimento, em especial a América Latina (FIORI, 2001. p. 84)
}

30 modelo "keynesiano" foi elaborado pelo economista inglês John Maynard Keynes e o argumento principal da sua teoria se pautava na defesa da intervenção do Estado na economia. 
papel do Estado que, embora devesse ser eficiente na regulação, se apresentaria de modo reservado no campo das políticas setoriais. Aqui temos as especificidades da primeira fase das reformas para os países latino-americanos cuja promessa de desenvolvimento, crescimento e modernização se consolidariam pela abertura da cooperação internacional, diminuição do tamanho do Estado, ajuste fiscal, reformas trabalhistas entre outras ações.

Segundo o documento do CLAD (1998) a primeira onda de reformas dos anos de 1990 não foi suficiente para solucionar os problemas da América Latina quanto à crise crônica do modo de gerir o Estado, dívida externa, aumento da desigualdade e injustiças nos mais diversos setores da sociedade.

Portanto, na década de 2000, emerge a segunda onda de reformas que embora, se assemelhe ao contexto de ajuste fiscal dos anos de 1990, traz outros desafios porque o problema não estava somente no tamanho do Estado, mas na eficiência dos resultados, por isso, a tendência do Estado em priorizar áreas como saúde educação uma vez que estes setores poderiam ser geridos à luz do gerencialismo. Entra em cena, então, medidas com perfil receituário pelas quais os governos poderiam superar suas crises ao investirem na competição, descentralização, desburocratização e qualidade total dos serviços. Neste caso, para a segunda onda reformista a prioridade seria a nova gestão cujo "problema fundamental é o fato de se ter um tipo inadequado de governo. Não necessitamos de mais ou menos governo: precisamos de melhor governo. Para sermos mais sucintos, precisamos de uma melhor atividade governamental" [...] um modelo de gestão mais eficiente e menos burocrática "reinventar o governo" (reinventing government) (OSBORNE ; GAEBLER, 1992, p. 25).

Aos poucos, abandona-se a ênfase no tamanho do Estado, cabendo a este, a gestão eficiente dos setores. Segundo documento do CLAD (1998), dois pontos foram essenciais para a implantação da Nova Gestão Pública, sendo: 1) a adoção da administração pública voltada para resultados, baseada em mecanismos de contratualidade da gestão, com metas, indicadores e formas de cobrar os gestores, transparência nas ações governamentais, oferecendo certo controle pelos cidadãos e o uso da accountability; 2) a flexibilização que favorece a responsabilização pelos resultados por meio de sistemas de controle e gerencialismo. Neste sentido, a governança pública eficiente foi o argumento basilar das economias centrais as quais mostravam ao mundo que o crescimento econômico ocorreria por conta da organização do Estado, numa fórmula desburocratizada e descentralizada. Esse mesmo argumento foi incorporado nas orientações do Fundo Monetário Internacional, por exemplo, ao afirmar que a Boa Governança, se constituía o primeiro passo para a modernização dos países periféricos, ou seja, um exemplo a ser seguido.

Para Osborne (1992) este cenário se corporificou por uma mudança paradigmática em relação à administração pública por parte do Estado, que trouxe novas conceituações gerenciais como Nova Governança Pública e accountability. Primeiramente sobre Governança, o autor escreve,

Não é uma expressão
recente, pois o termo traz
consigo uma notória
bagagem teórica e/ou
ideológica. Ainda segundo
o autor, os críticos
diferenciam três escolas
de governança na
literatura: (i) governança
corporativa - focada nos
sistemas internos e
processos que orientam o
rumo accountability das
organizações; (ii) "boa"
governança - associada a
elaboração de manuais e
códigos de governança; e
(iii) governança pública -
relacionada com a
participação da sociedade
no processo de de
implementação de
políticas públicas e de
melhoria da prestação de
serviços públicos.
(OSBORNE, 1992, p.89).

Igual perspectiva é apontada por Pereira (1997, p. 45) ao afirmar que "governança é a capacidade financeira e administrativa do Estado em implementar suas políticas", esse processo se difere de governabilidade no sentido da relação de legitimidade do Estado e sociedade porque amplia e agrega os interesses do setor privado diante da falta de recursos públicos e enfraquecimento do Estado. Criam-se códigos de valores e condutas modernas e desburocratizantes, as quais resultarão em 
eficiência e competitividade, categorias específicas do gerencialismo.

Especificamente sobre a definição de accountability, Brinkerhoff (2001, p. 02) afirma que o termo significa "prestar contas de forma transparente". Um dos aspectos que destacamos sobre a definição de accountability é que, embora haja, por parte da ciência política, diversos significados para o termo, a tendência é convertê-lo como informação, produto de todo processo administrativo, econômico ou educacional.

Após mostramos aspectos conceituais da Nova Gestão Pública, reiteramos ainda a forma como esse modelo de gestão adentrou os países em desenvolvimento. Tendo em vista que o formato de governança foi ideologicamente pensado pelos governos neoliberais para "fabricar" modelos de Gestão eficiente e imediata, claro, este formato seria visto positivamente, pela maioria dos países em desenvolvimento uma vez que, a primeira onda de reformas, como mostramos ao longo do texto, não foi suficiente para sanar as desigualdades, pelo contrário, acentuou as condições de pobreza em muitas localidades. Tanto que, dados apresentados pelo Centro Latino-Americano de Administração para o Desenvolvimento identificam que "um em cada três latinoamericanos estão na linha da pobreza extrema" (CLAD, p. 5). Se até então, as reformas realizadas, deliberavam restritamente sobre a questão do equilíbrio econômico, outra demanda entre em cena, qual seja, promover o desenvolvimento e a justiça social. Certamente que essas novas exigências representaram um "calcanhar de Aquiles" para as agências promotoras das reformas, que até então, profetizaram a prosperidade para a Região, mas sem lograr os resultados esperados.

Esse cenário corroborou para a divulgação e ampliação da Nova Gestão Pública nos países latino-americanos conforme exposto pelo CLAD (1998), processo que se constituiu a partir metas, a exemplo: estabelecer uma administração pública mais transparente, e nesse processo os gestores devem ser responsabilizados democraticamente perante a sociedade; descentralizar a execução dos serviços públicos que anteriormente se concentravam na esfera do governo central. Além dos ganhos de eficiência e efetividade, a descentralização aumenta o poder de fiscalização e o controle social dos cidadãos sobre as políticas públicas e seus resultados; consolidar uma administração Pública Gerencial orientada pelo controle dos resultados ${ }^{4}$; buscar formas que se afastem do controle burocrático e procedimental para se atentar aos ganhos de eficiência e efetividade das políticas a partir de indicadores de desempenho; controle contábil dos gastos pelos funcionários, conscientes dos custos no serviço público, fazendo bom uso do dinheiro de todos; Controle por competição administrada, ou por quasemercados, no sentido de oferecer o melhor serviço público aos usuários. Essa competição pode trazer ganhos de eficiência e efetividade ao sistema, já que a disputa obriga a utilização mais racional dos recursos; o controle social que se consolida pela ação avaliativa dos cidadãos sobre os serviços públicos; orientação da prestação dos serviços para o cidadão-usuário. Os cidadãos são chamados a assumir um papel ativo na organização da ação coletiva, e mais especificamente naqueles problemas que interferem no seu dia-a-dia e de suas famílias, a exemplo da segurança da comunidade, a gestão da escola dos filhos; responsabilização do servidor público cuja ação se pautará pela transparência e prestação de contas feitas por funcionários bem treinados e aptos a resolverem problemas de modo eficiente.

Diante desse cenário marcado por uma relação mais modernizada entre Estado, economia e sociedade, Clarke e Newman (2012, p. 354) analisam que "houve esforços compartilhados para liberar as forças do mercado do controle do Estado; liberar o consumidor da carga de impostos; e reduzir o tamanho, âmbito e custo do Estado". Vale ressaltar que este processo, forjado por intensas crises do capital, não afeta apenas a educação mas os direitos trabalhistas conquistados historicamente, com tendência a intensificação do trabalho sem melhorias dos salários, ou seja, acentua-se a exploração sobre a classe trabalhadora resultante de medidas que visam ao fortalecimento e ao restabelecimento do capital.

\footnotetext{
${ }^{4}$ Para este objetivo o CLAD (1998) afirma que a administração pública baseada nos resultados terá que investir fortemente na construção de instituições e no treinamento de pessoal qualificado, de modo a tornar possível a realização da avaliação de desempenho, tanto organizacional como individual. Esse é um ponto central da Reforma Gerencial do Estado. Neste sentido, o CLAD (1998, p.12) acredita que os Estados latino-americanos precisarão nos próximos anos montar sólidos sistemas de avaliação de desempenho, caso queiram de fato transformar as atuais estruturas da administração pública. Vale lembrar a correlação dessa meta, com a consolidação do Laboratório Latino Americano de Avaliação da Educação, destaque, também desta pesquisa.
} 
É desse cenário que reiteramos a importância da reflexão em torno do papel da educação escolar. Isso instiga tanto uma reflexão acerca do trabalho historicamente realizado por tal instituição, quanto em relação ao papel social que ela potencialmente tem condições de exercer com vistas a superação das desigualdades. Claro, sabemos que a escola sozinha não muda a sociedade, mas ela é peça central na formação da consciência e releitura do empírico que insiste em naturalizar as injustiças, especialmente no campo educacional. A importância da escola e dos conhecimentos científicos para formação integral do ser humano, apesar dos avanços neoliberais, é o que sinalizaremos a seguir.

\section{A EDUCAÇÃO ESCOLAR BRASILEIRA POSSIBILIDADES A PARTIR DA PEDAGOGIA HISTÓRICO-CRÍTICA}

No primeiro tópico do artigo, demonstramos como a educação brasileira tem sido desenhada pelo formato neoliberal e instrumentalizada pelas práticas da Nova Gestão pública. Mas seria essa a sentença final para a educação do país? E o que fazer com as teorias e pesquisas que almejam uma educação para além do capital, a exemplo da pedagogia históricocrítica?

Com a perspectiva da educação omnilateral, apesar do cenário desanimador, é que construímos a segunda parte dessa reflexão. Que a ingenuidade não pareça ser o nosso motor, mas a segurança de pensar na teoria e na prática educativa pelo viés da práxis formativa. Não nos afastaremos desse desejo.

Primeiramente, olhemos com expectativa para a década de 1980 que consagrou um período de retomada de ideais democráticos advindos de um movimento que visava à superação do modelo ditatorial que gerenciou o país durante 21 anos. Ciavatta (2014) destaca significativas conquistas obtidas na educação brasileira, fruto da luta dos trabalhadores da educação, evidenciando a escola como campo de ação em defesa da educação omnilateral.

Não obstante as frustrações da democracia representativa, temos espaços de palavra e de ação para prosseguir nos embates. Um destes se mantém ao longo dos anos, no campo trabalho e educação. Seus principais antecedentes são as lutas em defesa da escola pública na campanha pela LDBEN (Lei n. 4.024/61), contra a Ditadura (19641985), por uma nova Constituição (1988) e uma nova LDB (Lei n. 9.394/96), pela revogação do Decreto n. 2.028/97; pela defesa da formação integrada (Decreto n. 5.154/03, posteriormente incorporado à LDB pela Lei n. 11.941/08) (CIAVATTA, 2014, p. 197).

Tais conquistas avançaram em direção à melhoria da qualidade da educação escolar, à universalização do acesso à escola pública, gratuita, laica, igualitária e para todos. Em meio a frustrações, avanços e retrocessos, muitas foram as conquistas da classe trabalhadora, permanecendo um longo caminho pela frente a fim de alcançar novos objetivos.

Ocorreu no âmbito da educação escolar, tanto na formulação de documentos oficiais, de políticas educacionais e de diretrizes pedagógicas, quanto na formação de professores e nas reflexões acerca do processo de ensino aprendizagem. Avultou-se a presença de teorias críticas da educação, como a pedagogia históricocrítica, que foi uma das que mais se destacou e cuja base teórica fundamenta-se na perspectiva do materialismo histórico e dialético. Constituise, portanto, numa pedagogia de base revolucionária que guarda em sua raiz a crítica ao modelo capitalista de organização da sociedade.

Sem desconsiderar todas as contradições presentes no processo de "institucionalização" da pedagogia histórico-crítica enquanto fundamento pedagógico para a organização da educação escolar, sua presença em documentos escolares e diretrizes para a educação, em alguns Estados, foi um significativo avanço em favor da classe trabalhadora, bem como em favor do movimento de redemocratização do país (BACZINSKI, 2011). Mesmo que na prática pedagógica poucos fatores tenham sido modificados, garantiu-se, ao menos teoricamente, à educação escolar um espaço de luta por melhores condições de trabalho e a ampliação do acesso ao conhecimento escolar.

Isso possibilitou aos trabalhadores da educação uma reflexão crítica acerca do papel reprodutor que a escola exerceu desde sua 
institucionalização no capitalismo e o despertar para a urgente necessidade de suprimir o modelo reprodutor da educação escolar.

A qualificação crescente de profissionais envolvidos com a educação básica em nível de mestrado e doutorado é outro fator que merece destaque. A formação em nível de pós-graduação stricto sensu, tem fortalecido a luta em prol da classe trabalhadora, alimentada por ideais progressistas em defesa da luta revolucionária compreendendo que a educação compõe a luta de classes, enquanto arma ideológica que capacita os sujeitos rumo a superação da alienação, exploração e da exclusão social.

A formação de novas consciências políticas corrobora com a luta por uma educação escolar universalista, que se coloca em confronto com a falsa universalidade na educação impressa pela hegemonia burguesa e ao enfrentamento contra as práticas de racismo, sexismo, homofobia e a lesbofobia, transfobia, a desvalorização do trabalhador do campo, das comunidades indígenas, quilombolas, a fragilidade no processo de inclusão daqueles que possuem necessidades especiais de atendimento, entre outros fatores que contribuem para a fragmentação e o caráter dualista na oferta da educação escolar. Neste caso, a defesa da universalidade da educação consiste, portanto, na luta pela superação das condições desiguais de educação e da cultura a que os diferentes grupos sociais têm acesso (SAVIANI, 2003).

Pelas décadas de luta em defesa da educação de qualidade é que consideramos a importância da atividade pedagógica aliada a outros fatores indispensáveis, como o envolvimento de todos os profissionais da educação em práticas educativas dimencionadas, as quais tornem possível a formação integral do ser humano, num nível de consciência social e política, sustentado por todo o conhecimento científico e tecnológico desenvolvido pela humanidade ao longo de sua história coletiva.

E viável afirmar então, que as escolas brasileiras têm o acesso ao aporte teórico para se constituir enquanto instituição promotora do desenvolvimento humano, nos aspectos cognitivo, psicológico e corporal com potencialidade para ultrapassar os propósitos capitalistas, contribuindo de forma direta e intencional com a superação do status quo que a emoldura. Mas é preciso ter em vista a superação da formação para o mercado de trabalho e avance em direção à formação do ser humano integral, conforme defendem Konder (2009) e Pistrak(2011), ou seja, o homem que domine as tecnologias e habilidades profissionais, além de diferentes modos de pensar e agir de acordo com a ética, valorizando os sentidos, os sentimentos e as emoções, a arte e a estética que balizarão as ações do sujeito também no âmbito da política, da vida econômica, social e cultural, no desenvolvimento intelectual, no raciocínio lógico, científico, filosófico, político, nas capacidades de localização no espaço e no tempo histórico, no domínio de tecnologias, na exploração do corpo e nas atividades manuais, tão caras ao ser humano intelectualizado .

Sinalizamos que o movimento de renovação cultural é dialético e pode fortalecer o processo de revolução social e econômica, por meio da mudança de consciência, provocada pelas relações sociais rumo a um novo modo de compreender as coisas, de agir, de viver, logo, de organizar a sociedade como um todo.

Segundo Estévez (2003), a formação estética tem relevante papel diante do objetivo de renovação cultural. A formação estética, portanto, deve se constituir de modo aliado e fortalecedor do desenvolvimento humano em vista do trabalho, da formação técnica e profissional, aspectos indispensáveis para a formação do novo homem. Mesmo com a superação do capitalismo, a humanidade continuará necessitando do desenvolvimento social, cujo motor é o trabalho. Portanto, a defesa da educação estética na formação do ser humano omnilateral deve ser compreendida como um elemento a mais vinculado diretamente à formação profissional, técnica e científica do sujeito, proporcionada pela educação escolar.

Também pela arte como meio de sensibilização, de humanização, como contribuição ao desenvolvimento da sensibilidade e das emoções humanas, contrapondo-se aos ideais capitalistas, que utilizam a manifestação artística como um paliativo diante das dificuldades da vida, como um calmante que provoca um adormecimento diante das situações de injustiça. Assim como afirma Snyders (1977, p. 310), vê-se "a cultura como calmante, bálsamo, compensação para a vida tal como ela é, resignação à vida tal como ela é". Ou ainda: "o homem se eleva, se afirma, transformando a realidade, humanizando-a, e a arte com seus produtos satisfaz essa necessidade de humanização" (VÁZQUEZ, 2011, p. 43). Não estando limitados às disciplinas ligadas à 
educação artística nem mesmo à educação escolar, os resultados da educação estética se expandem e atingem as relações como um todo, entre os homens na sociedade, entre a humanidade e a natureza, pois o homem, continuará desenvolvendo-se fora da escola, nas relações com outros homens, na sociedade, no trabalho, nos partidos políticos, na comunidade, porém, sua formação sistematizada se dará na escola.

Ao debater sobre a necessária ampliação do papel da escola em vistas à formação integral do ser humano, torna-se fundamental problematizar que ela se constitui por contradições, mas, indicar contradições constitutivas da educação escolar brasileira, só e possível se entendermos essa categoria, não como uma negatividade, mas ao contrário, como um movimento fértil e positivo, por meio do qual encontram-se novos caminhos que justifiquem a luta por uma educação de caráter omnilateral.

A organização da atividade
pedagógica promotora
[do] desenvolvimento
humano omnilateral
requer formação teórica,
apreensão do movimento
de constituição da
realidade
desenvolvimento
humano, posicionamento,
organização e atuação
políticas, diante das
condições históricas das
relações sociais fundadas
sob a égide do capitalismo
(UMBELINO, 2014, p. 278)
[grifos da autora].

Dessa forma, importa afirmar que, mesmo colocando a educação escolar e as ações pedagógicas mediadas pela práxis, no centro da reflexão acerca da formação humana omnilateral, não se constitui numa definição estreita, pois uma atividade pedagógica emancipadora carece de um envolvimento coletivo, de posicionamentos teóricos revolucionários, bem como de práticas políticas por parte dos profissionais da educação, com o objetivo de compreender tanto a realidade social como o processo de desenvolvimento e aprendizagem humana, para então transformá-las.

Numa referência mais estreita ao materialismo histórico, identificamos que a organização de uma formação omnilateral da pessoa implica dividir a formação em quatro grandes eixos - Trabalho Produtivo; Educação Intelectual; Educação do Corpo; Educação Técnica - aos quais se podem acrescentar inúmeras variáveis (MARX, 2012). Os referidos eixos serão problematizados individualmente com o objetivo de reconhecê-los como elementos da prática educativa, no entanto, cada um deles encontram-se interligados, como partes de um todo. Portanto, o limite entre um e outro é quase inexistente.

O primeiro eixo refere-se ao Trabalho Produtivo, o qual guarda a necessidade de transformação da natureza; o domínio de técnicas e tecnologias; a preocupação com a coletividade; a produção de bens de consumo necessários à vida, bem como a manutenção e a evolução da espécie humana. A própria humanização.

O trabalho constituidor da vida se faz a partir de duas grandes dimensões, enquanto produtor de mercadorias para o consumo e sustentação da humanidade, e enquanto produtor da própria humanidade, devido à capacidade dos homens de transformarem a natureza a fim de atender suas necessidades. Fazem isso por meio do trabalho (MARX, 2012). Na redação final do Programa de Gotha, Marx define o trabalho como;

[...] fonte de toda riqueza e toda cultura, e como o trabalho universalmente útil só é possível por meio da sociedade, o produto total do trabalho [gesamte Arbeitsprodukt] pertence à sociedade, isto é, a todos os seus membros, com obrigação universal ao trabalho, com igual direito, a cada um segundo suas necessidades razoáveis (MARX, 2012, p. 89) [1875].

Inferir o trabalho dessa forma remete à defesa de que todo ser humano se desenvolve e se humaniza mediado pelo trabalho, portanto, desde a menor idade (infância) tem o direito de se desenvolver e de transformar o meio em que vive e fruir do resultado de tal transformação.

Marx e Engels (1978) [1866], ao definir a formação integral, afirma que o trabalho produtivo deve ser combinado a outros três 
eixos, a Educação Intelectual, a Educação do Corpo - física - e a Educação Tecnológica ${ }^{5}$. Com base na definição de Marx, torna-se pertinente avançar no debate, reforçando a compreensão de que o homem é um ser histórico e social, que se forma e se transforma mediado por múltiplas determinações, dentre as quais o trabalho produtivo, o qual se configura como princípio educativo. Isso evidencia, contudo, a omnilateralidade como elemento fundante da formação humana tendo como horizonte a emancipação.

Segundo a teoria marxiana, o trabalho que constituiu o ser humano não fica restrito ao sentido da produção material que resulta na posse, no ter. Tal conceito de trabalho enquanto propriedade e produção de bens materiais individuais, praticado sob a égide do capital, não é promotor da vida e da liberdade, não possibilita ao ser humano apropriar-se de seu ser de modo omnilateral. Contrário a isso, na sociedade organizada sob a razão capitalista, o ser humano é incitado a apreender-se de modo unilateral.

Por tal razão, ao vislumbrar o desenvolvimento omnilateral do ser humano que implica sua formação intelectual, corporal, tecnológica, politécnica, sensível, imagética, artística, musical, estética, ética, política, entre inúmeras outras - e a sua capacidade de desfrutar de modo total (omni) da natureza e o produto de sua transformação, remete à superação da sociedade de classes como condicionante para se alcançar plenamente a omnilateralidade (MARX, 1978).

Em valorização ao movimento dialético, ao qual a sociedade e as relações humanas estão submetidas, é preciso considerar que o horizonte que revela a possibilidade da emancipação humana é fruto do movimento real e concreto da história da humanidade sendo, portanto, marcado por inúmeros fatos que impulsionam o intrincado movimento que ora avança, ora retrocede em direção à emancipação. Configurase, assim, o processo de estruturação e desestruturação da sociedade capitalista.

Embora Marx (2012) expunha que o capital não favorecerá o desenvolvimento humano omnilateral, alerta que não há impedimento para iniciar o processo em busca da formação plena ainda nos limites deste sistema econômico. Tais razões justificam a necessidade

\footnotetext{
${ }^{5}$ Marx apresenta essa concepção de desenvolvimento humano no documento "Instrução para os delegados do Conselho Central Provisório a propósito de diversas questões".
}

imperiosa de pugnar por uma formação humana que tenha em seu fundamento a omnilateralidade, requerendo a defesa por uma educação escolar que seja ajustada com tais ideais, para que assim possa ser forjado, no ceio da sociedade capitalista, o caminho para a formação omnilateral.

A educação intelectual, definida por Marx (2012) como um eixo do processo formativo omnilateral, abrange o desenvolvimento do raciocínio lógico, da língua materna, da gramática, da literatura, de línguas estrangeiras, dos conceitos geográficos, históricos, de matemática, física, química, das ciências, do desenvolvimento da inteligência artística (artes visuais, plásticas musicais, cênicas...) e da retórica.

O aprimoramento das capacidades racionais, propriamente humanas, se dá pela educação intelectual, cujos resultados refletem diretamente na evolução científica e técnica no âmbito do trabalho e das relações sociais. A acuidade racional e científica dos sujeitos é condição indispensável ao processo de humanização do ser. Não é possível formar um sujeito revolucionário sem que previamente ele se aproprie da ciência existente. Sem o domínio intelectual dos conhecimentos científicos que estruturam a sociedade atual, não se atinge um patamar superior à alienação imposta à classe trabalhadora (SAVIANI, 2003).

É preciso, portanto, investir em aulas dedicadas à exploração dos conhecimentos historicamente produzidos pela humanidade, aproximando, especialmente aos sujeitos da classe trabalhadora, a ciência da arte, da poesia, da literatura, das reflexões filosóficas e sociológicas, como caminho para o conhecimento das invenções tecnológicas. O processo de ensino e aprendizagem carece de uma estrutura curricular que garanta a apropriação científica iniciada já na educação infantil, resguardando as características metodológicas que cada faixa etária exige (BACZINSKI, 2017).

A disciplina de estudos empregada por professores e alunos não deve ser secundarizada nesse processo. Por um longo período, que se estende até os dias atuais, o conceito de disciplina foi entendido de modo negativo, relacionado à postura autoritária do professor e à ausência de autonomia por parte do aluno. Tais posturas necessitavam ser superadas; no entanto, perdeu-se sua essência na medida em que a disciplina foi conduzida a outro extremo. 
De um lado, se tem a disciplina como postura autoritária e repressora e, de outro, uma defesa desmedida pela autonomia do aluno e a descaracterização do papel do professor. Tudo isso justificado pela necessidade de uma relação democrática no processo de ensino e aprendizagem (SAVINAI, 2003; DUARTE, 2004).

Todos esses elementos que engendram a prática pedagógica necessitam ser abarcados por um processo avaliativo coerente com o desenvolvimento intelectual humano, em corroboração ao processo formativo científico, mediado por práticas que instigam a aprendizagem, superando, contudo, a concepção de avaliação que há decadas é difundida pelos organismos internacionais, ou seja, como um mero instrumento de verificação dos resultados quantitativos daquilo que foi aprendido ou não.

Para Saviani(2010) o desenvolvimento intelectual amplo, provocativo e impulsionador do desenvolvimento total do ser humano é fruto de um processo de escolarização rigoroso, científico, disciplinador e amoroso, que socializa os conhecimentos científicos e proporciona sua apropriação por parte do educando. Isso humaniza e eleva o ser humano a uma condição superior de conhecimento, quando comparada com aquela prevalecente no início do percurso escolar, quando se efetiva a passagem do conhecimento sincrético para o sintético de modo definitivo.

A Educação do Corpo, segundo eixo da formação omnilateral, definida por Marx (2012), consiste no desenvolvimento da força, do equilíbrio, das habilidades motoras, da autoconfiança, da aceitação e do respeito às regras - e/ou da criação de regras, da corporeidade, incluindo as questões próprias da criança, do homem e da mulher, do autoconhecimento e do reconhecimento do meio externo mediados pelos órgãos dos sentidos (olfato, visão, audição, tato e paladar) e dos sentidos práticos como o amor, a vontade e a imaginação. $O$ desenvolvimento do corpo é tão importante quanto o da mente, por serem elementos intrínsecos. $O$ ser humano é constituído por um complexo sistema de corpo e mente, por meio do qual o desenvolvimento de um está atrelado ao outro e a aprendizagem impulsiona o desenvolvimento de ambos. É urgente reconhecer que o desenvolvimento do corpo, juntamente com o desenvolvimento intelectual, perfaz a totalidade do ser humano.
Para o reconhecimento de si enquanto parte de um meio externo, é imprescindível o autoconhecimento e o domínio do próprio corpo, cujo processo é permeado por desafios que levam o ser humano a reconhecer seus limites, bem como a superá-los. Promovendo o desenvolvimento da força, do equilíbrio e da autoconfiança. A educação do corpo capaz contribui com a formação omnilateral a qual requer a superação da concepção biológica que a educação física carregou por muito tempo na educação brasileira, indo além também do caráter simplista de treinamento esportiva( ZUKI, 2012). A educação dos sentidos, como parte da educação do corpo, permite ao ser humano a apropriação sensível do mundo. A natureza objetiva se torna humanizada pela mediação do homem. Quer dizer, o ser humano só pode se apropriar da natureza e torná-la humana por meio dos sentidos. Portanto, a educação do corpo contribui para o desenvolvimento dos sentidos, das sensações e das emoções que elevam o sujeito à apropriação de sua identidade e ao estabelecimento de sua relação com o mundo e consigo mesmo.

O desenvolvimento dos sentidos ocorre em íntima conexão com o desenvolvimento do corpo, cuja evolução contribui com o progresso do trabalho manual e intelectual. A promoção da educação física aliada à formação integral do ser humano, se tornará possível por meio de ações sistemáticas e intencionalmente conduzidas por outrem, ou seja, pelo educador escolar.

A educação física, ao promover o desenvolvimento do corpo e o seu conhecimento, possibilita a apropriação de conhecimentos científicos relativos à biologia, à antropologia, à linguagem, à expressão corporal, ao trabalho produtivo, ligados por uma dimensão política que promove a reflexão sobre as condições necessárias para o desenvolvimento do corpo (higiene, saneamento básico, alimentação saudável), indispensáveis a todo ser humano (ZUKI, 2012).

A concepção da educação corporal a partir do conceito da corporalidade (que entende as expressões do corpo como resultado das manifestações historicamente produzidas pela humanidade) amplia o campo de trabalho da educação física nas escolas, promovendo uma estreita relação com todos os demais eixos teóricos e práticos que compõem a estrutura curricular da escola e compondo, dessa forma, uma práxis pedagógica inovadora. 
Por fim, o terceiro eixo formativo pautase na Educação Tecnológica, corresponde a formação politécnica, o domínio das diferentes tecnologias, a integralização da ciência e da técnica, a apropriação técnica e científica de diferentes profissões, onde se inclui a formação para o trabalho. Entende-se o trabalho como constituidor da vida e não como seu destruidor tal qual prevalece no capitalismo (MARX, 2012).

Essa formação, assim como as demais já anunciadas, consiste numa tarefa da educação escolar. O educando, desde a mais tenra idade, deve ser inserido no mundo tecnológico, intrínseco ao mundo do trabalho. A formação politécnica, cuja definição se aplica com mais coerência à pretensão de Marx (2012) quando tratou da formação tecnológica, presume uma conexão entre o trabalho manual e o intelectual que permita ao sujeito não apenas conhecer diferentes técnicas de trabalho/produção, mas sim, ser capaz de compreender as formas com que o trabalho produtivo funciona e se organiza.

A politecnia, portanto, é um modo de formação que promove na mesma medida a formação teórica e a prática. Entende-se por formação prática, o domínio das leis que regem o modo de produção capitalista e suas principais técnicas de labor. E por formação teórica, a compreensão da organização do mundo do trabalho e as relações entre aqueles que vendem sua força de trabalho com os que se apropriam dessa. Ou seja, trata-se de uma formação escolar aliada ao trabalho produtivo.

Por meio da educação sistemática, o sujeito precisa ter a oportunidade de conhecer as diferentes tecnologias, por serem produtos do trabalho humano (ciência), compreender o processo pelo qual ocorreu sua evolução, para que assim possa contribuir de forma direta com seu contínuo progresso e/ou transformação (SAVIANI, 2014).

A socialização dos conhecimentos relativos à tecnologia por meio da escola é um caminho para a superação da alienação em que o ser humano, especialmente aquele pertencente à classe trabalhadora, tem sido submetido ao longo da história da humanidade. Portanto, faz-se necessária uma escola equipada com biblioteca, laboratórios de informática, química, física, biologia, geografia, matemática e assim progressivamente, que proporcione às novas gerações a introdução ao ensino da ciência tecnológica pela aproximação aos conhecimentos de robótica e microeletrônica. E uma proposta de conceder aos estudantes o domínio teórico e prático das relações de produção próprias da razão capitalista, compreendendo, dessa forma, toda a complexidade invólucro ao mundo do trabalho, sem dissociação com a formação humana, intelectual e física. Konder (2009) afirma que é necessário dotá-los de conhecimento científico e uma nova consciência acerca da sociedade em que vivem, a fim de formar sujeitos capazes de fortalecer o movimento de superação do capitalismo.

A escola não tem o poder de eliminar as diferenças de classe, nem mesmo a estratificação social, de modo heróico e isolado. Mas certamente tem a iminência, ainda que latente, de diminuir as diferenças quanto ao acesso ao conhecimento científico. Ela tem o potencial de munir a classe trabalhadora com conhecimento e amplo desenvolvimento humano, tornando-a capaz de encampar a luta pela superação da condição de alienação imposta pelo modo de produção capitalista.

Quanto mais complexas se tornam as relações sociais e econômicas da sociedade, tão maiores são as possibilidades de desenvolvimento humano. Tendo em vista que o ser humano evoluiu historicamente por meio da sua relação com a natureza/sociedade, o constante avanço nas produções tecnológicas permite a ele um contínuo desenvolvimento de suas capacidades (intelectuais, físicas, emocionais, tecnológicas). Portanto, as potencialidades latentes no ser humano são ilimitadas, impossíveis de serem previstas e projetadas.

Diante da contínua evolução do ser humano, provocada pelas relações sociais em constante modificação e complexificação, para pensar uma formação omnilateral que fundamente uma pedagogia marxista, torna-se coerente dar um passo à frente no caminho aberto por Marx. Os três eixos da educação por ele anunciados - educação intelectual, física e tecnológica - e a sua relação com o trabalho produtivo, carecem de ampla problematização quando olhadas sob a lente da realidade atual.

Mas elaborar uma pedagogoa para além do capital e que sustente um projeto de educação para a emancipação, exige um trabalho coletivo, amplamente debatido pelos profissionais da educação e toda a comunidade escolar, apropriando-se da vasta produção teórica já existente acerca de cada um dos eixos propostos por Marx (2012), aprofundando-os e 
mantendo seu caráter unitário. Devem ser desafiados pela necessidade de problematizar as lateralidades humanas e atualizá-las constantemente, em atendimento ao movimento dialético próprio das relações humanas.

Os embates políticos vivenciados pela sociedade brasileira em tempos atuais refletem a contribuição da educação escolar para a formação dos seres humanos deste tempo. Apesar de todas as limitações sofridas pela escola, circunscrita ao modelo capitalista que domina a organização social atual, tal instituição tem formado sujeitos que - mesmo timidamente - mostram-se mais esclarecidos e críticos politicamente e mais sensibilizados moralmente. Posicionam-se diante dos problemas enfrentados por aqueles que vivem à margem da sociedade de classes, assim como se têm mobilizado em defesa da classe trabalhadora, reconhecendo-se como parte desta (BACZINSKI, 2017).

\section{CONSIDERAÇÕES FINAIS}

Acreditamos que pedagogia históricocrítica, enquanto teoria crítica da educação elaborada no Brasil na década de 1970, em contínuo processo de criação, levada a cabo por um significativo grupo de intelectuais brasileiros, tem contribuído fortemente na feitura de um trabalho pedagógico que almeja a emancipação humana.

Ela propaga ideais revolucionários e reconhece a escola como espaço de luta política, potencialmente capaz de contribuir com 0 processo de transformação social. Com suas bases teóricas fundamentadas no materialismo histórico e dialético, a teoria objetiva a realização de processos educativos em razão da formação integral do ser humano. Defende a oferta da educação escolar laica, universal, gratuita, em tempo integral, de caráter omnilateral, conjugando teoria e prática. Saviani(2010) afirma que a pedagogia histórico-crítica tem contribuído com o encorajamento de educadores e educandos para a institucionalização de atividades revolucionárias, bem como tem sustentado teoricamente a defesa da superação da educação dualista e unitária predominante na sociedade brasileira.

Tomar esta pedagogia como base para um projeto revolucionário social e educacional visando à formação humana omnilateral é sinalizar ce garantir a apropriação efetiva pelo indivíduo singular do patrimônio cultural, científico e tecnológico da humanidade, a fim de atingir o nível de formação integral, cujo resultado é a criatividade, a liberdade e a humanização plena. Além de tonificar o campo educacional como espaço político em favor do trabalhador, desvendando as intenções de exploração e alienação e com isso ampliando os espaços de luta que favorecem mudanças no papel do Estado em relação aos objetivos públicos da educação e da escola

Tudo isso é subsidiado por concepções de ser humano, de sociedade e de educação que superam o modelo imposto pelo capital. Corresponde à escola o ofício de ultrapassar o estereótipo afixado pelas tendências Tradicional/religiosa e Nova, elevando o sujeito a capacidades tanto intelectuais, como manuais e sensíveis, promovendo o pleno desenvolvimento de suas faculdades. Tal desenvolvimento é suscitado pela socialização do conhecimento científico sem desmerecimento dos aspectos estéticos, físicos e sensitivos, cuja associação cumulativa de todos esses elementos é capaz de desenvolver $O$ ser humano omnilateral (BACZINSKI, 2017).

A formação humana omnilateral, portanto, não se efetivará por meio de ações espontâneas e superficiais, pois demanda dedicação e concentração por parte de todos os envolvidos. Para alcançar o pleno desenvolvimento humano, mediado por ações escolares e sistematizadas, requer ações práticas no âmbito da política educacional, da organização do sistema educacional, de ações pedagógicas resultantes do empenho dos profissionais da educação, bem como do esforço e dedicação do sujeito que será formado (BACZINSKI, 2017).

A omnilateralidade se constituirá por um amplo movimento político e pedagógico, imbricado pelo reconhecimento do modo em que a sociedade se organiza, suas relações sociais, políticas, econômicas e culturais, que se convertem em múltiplas determinações na formação do ser social e na organização da educação escolar. Requer, ainda, compreensão acerca do desenvolvimento humano, suas limitações e capacidades. Para então, subsidiada pelo conhecimento científico, reagir aos condicionantes estabelecidos pela sociedade, sustentada por um posicionamento crítico, político e participativo que estabeleça novas relações sociais.

Só assim, será possível alcançar um nível de desenvolvimento em que o ser humano usufrua do máximo de suas capacidades físicas e 
intelectuais, conquistando um grau de liberdade e criatividade frente à natureza e à sociedade. Isso possibilitará ao sujeito reconhecer-se enquanto indivíduo e, ao mesmo tempo, perceber-se enquanto ser universal, ultrapassando, contudo, os limites do individualismo.Movidos pela diáletica, cremos que precisamos encontrar brechas no sistema atual que permita o avanço em direção a um novo modelo de organização social feito pelo coletivo dos trabalhadores, na busca por espaços, além de manter e fortalecer a luta por avanços e reformulações nas leis e planos para a educação. A classe trabalhadora, e aqui inclimos, principalmente os trabalhadores da educação, devem permanecer vigilante e atuante em diferentes frentes de luta em prol da educação nacional e universalizada. Mantendo viva a afirmativa de Marx, na Tese 11 sobre Feuerbach, "os filósofos apenas interpretam o mundo diferentemente, importa é transformá-lo" (MARX e ENGELS, 2007, p. 29) [1846].

\section{REFERÊNCIAS}

ANDERSON, P. Balanço do neoliberalismo. In: SADER, Emir; GENTILI, Pablo (Orgs). Pósneoliberalismo: as políticas sociais e o Estado democrático. Rio de Janeiro: Paz e Terra, 1995, p. 9-23.

BACZINSKI, A. V. M. A implantação oficial da Pedagogia Histórico-Crítica na rede pública do estado do Paraná (1983-1994): legitimação, resistências e contradições. Campinas: Autores Associados, 2011.

BACZINSKI, A. V. M. Educação escolar brasileira: possibilidades e limites para uma formação de caráter omnilateral. Pelotas, 2017. Tese (Doutorado em Educação) Faculdade de Educação, Universidade Federal de Pelotas, Pelotas, 2017.

BATISTA, Paulo Nogueira. O Consenso de Washington: a visão neoliberal dos problemas latino-americanos. Caderno da dívida externa, $\mathrm{n}$. 69, p. 1-35, set. 1994.

BRINKERHOFF, Derick W. Taking Account of Accountability: a conceptual overview and strategic options. Washington, DC: Abt Associates; Agency for International Development Center for Democracy and
Governance Implementing Policy Change Project, Phase 2, 2001.

CASASSUS, Juan. A Reforma Educação na América Latina no Contexto da Globalização. Cadernos de Pesquisa, n. 114, p. 7-28, nov. 2001.

DUARTE, N. Vigotski e o "aprender a aprender": crítica às apropriações neoliberais e pósmodernas da teoria vigotskiana. 3.ed. rev. e ampliada. Campinas: Autores Associados, 2004.

CIAVATTA, Maria. O ensino integrado, a politécnica e a educação omnilateral. Por que lutamos? Trabalho \& Educação, Belo Horizonte, v. 23, n.1, p. 187-205. Jan./abr., 2014. Disponível em:

http://www.portal.fae.ufmg.br/seer/index.php/tr abedu/article/view/1919. Acesso em: $10 \mathrm{mar}$. 2016.

CLARKE, John; NEWMAN, Janet. Gerencialismo. Educação e Realidade, Porto Alegre, v. 37, n. 2, p. 353-381, maio/ago. 2012.

ESTÉVEZ, Pablo René. A educação estética: experiências da escola cubana. São Leopoldo: Nova Harmonia, 2003.

FIORI, José Luiz. 60 lições dos 90: uma década de neoliberalismo. Rio de Janeiro: Record, 2001.

FONSECA, João José Saraiva. Metodologia da pesquisa científica. Fortaleza: UEC, 2002.

KONDER, Leandro. Marxismo e alienação contribuição para um estudo do conceito marxista de alienação. São Paulo: Expressão Popular, 2009.

MARX, Karl; ENGELS, Friedrich. Crítica da educação e do ensino. Lisboa: Moraes, 1978.

MARX, Karl; ENGELS, Friedrich. Crítica ao programa de Gotha. São Paulo: Boitempo, 2012.

OSBORNE, Stephen P. The (new) public governance: a suitable case for treatment? In: OSBORNE, Stephen P. (Ed.). The new public governance: emerging perspectives on the theory and practice of public governance. Abingdon: Routledge, 1992.p. 12-32 
PEREIRA, Luiz C. Bresser. A Reforma Gerencial do Estado de 1995. Revista de Administração Pública, n. 34, p. 55-72, jul. 1997.

PISTRAK. Fundamentos da escola do trabalho. 3 ed. São Paulo: Expressão Popular, 2003.

SAVIANI, Demerval. Pedagogia histórico-crítica: primeiras aproximações. 8 ed. revis. e ampl. Campinas: Autores Associados, 2003.

SAVIANI, Dermeval. O lunar de Sepé: dilemas e perspectivas na educação. Campinas: Autores Associados, 2014.

SNYDERS, Georges. Escola, classe e luta de classes. Lisboa - Portugal: Moraes Editores, 1977.

UMBELINO, Janaína Damasco. Elementos mediadores na atividade pedagógica promotora do desenvolvimento humano na criança: contribuições da educação em Cuba. 2014. 459 f. Tese (doutorado) - Universidade Federal de Santa Catarina, Centro de Ciências da Educação. Programa de Pós-Graduação em Educação. Florianópolis, SC, 2014.

UNESCO - Centro Latino-Americano de Administração para o Desenvolvimento-CLAD. Uma nova Gestão Pública para a América Latina, 1998. Disponível em: http://www.bresserpereira.org.br. Acesso em 10 fev. 2018.

VÁZQUEZ, Adolfo Sánchez. As ideias estéticas de Marx. Tradução: Carlos Nelson Coutinho. 3 ed. São Paulo: Expressão Popular, 2011. 